13.O'Reilly, D.R., L.K. Miller, and V.A. Luckow. 1992. Baculovirus Expression Vectors: A Laboratory Manual. Freeman, New York.

14.Paciotti, G.F. and L. Tamarkin. 1988. Interleukin-2 differentially affects the proliferation of a hormone-dependent and a hormone-independent human breast cancer cell line in vitro and in vivo. Anticancer Res. 8:1233-1239.

15.Pham, M.Q., S. Naggie, M. Wier, H.J. Cha, and W.E. Bentley. 1999. Human interleukin2 production in insect (Trichoplusia ni) larvae: the effects and partial control of proteolysis. Biotechnol. Bioeng. 60:165-172.

16. Rosenburg, S.A., E.A. Grimm, M. McGrogan, M. Doyle, E. Kawasaki, K. Koghs, and D.F. Mark. 1984. Lymophokine activated T cells in the treatment of cancer. Science 223:1412-1415.

17.Smith, G.E., M.J. Fraser, and M.D. Sum mers. 1983. Molecular engineering of the $\mathrm{Au}$ tographa califonica nuclear polyhedrosis virus genome: deletion mutations within the polyhedrin gene. J. Virol. 46:584-593.

18.Summers, M.D. and G.E. Smith. 1987. A manual of methods for baculovirus vectors and insect cell culture procedure. Texas Agricultural Experiment Station Bulletin No. 1555.

19.van der Wilk, F., J.W.M. van Lent, and J.M. Vlak. 1987. Immunogold detection of polyhedrin p10 and viron antigens in Autographa califonica nuclear polyhedrosis virusinfected Spodoptera frugiperda cells. J. Gen. Virol. 68:2615-2624.
Address correspondence to Dr. William E. Bentley, Department of Chemical Engineering, University of Maryland, College Park, MD 20742, USA. e-mail: bentley@ eng.umd.edu

Received 15 October 2001; accepted 19 February 2002.

H.J. Cha, N.G. Dalal, M.-Q. Pham, S.F. Kramer, V.N. Vakharia, and W.E. Bentley University of Maryland College Park, MD, USA

For reprints of this or any other article, contact Reprints@BioTechniques.com

\section{Increased Efficiency of Cloning Large DNA Fragments Using a Lower Copy Number Plasmid}

BioTechniques 32:992-998 (May 2002)

The advent of recombinant DNA technology has revolutionized biological and genetic research $(9,10)$. These technologies have allowed us to perform previously unthinkable tasks, such as the sequencing of the human genome and the deletion of a gene of interest in animal models $(6,14,21)$. Most of the commonly used cloning vectors are derived from bacterial plasmids, which are self-replicating extrachromosomal DNA molecules found in virtually all bacterial species $(1,9)$. Most plasmids are double-stranded, circular DNA molecules, and their replication is coordinated with that of the bacterial host $(16,19)$. Plasmid vectors used for molecular cloning are primarily derived from $E$. coli plasmids. These vectors possess three common features: a replicator, at least one antibiotic selectable marker, and a multiple cloning site (MCS). The replicator is a stretch of DNA sequence that contains the origin of replication (ori) and encodes the RNAs and proteins required for plasmid replication in host cells. Although the mechanisms underlying plasmid copy number control are still the subject of extensive investigations, it is believed that the replicator may play a pivotal role in determining the copy number of a given plasmid in different host cells $(11,20)$. Most cloning vectors contain a replicator derived from the prototypic ColE1 origin. Although both pBR322 and pUC19 plasmid vectors contain similar replicators from the ColE1-related pMB1 $(4,13)$, subtle changes in the replicators render them significantly different in their ability to maintain their copy number in host cells. As a result, in most host cells, the pBR322 vector is maintained at 100-300 copies per cell, whereas the pSL301plasmid with the pUC19 replicator contains 1000-3000 copies per cell $(3,5,22,25,26)$.

Although recombinant DNA technology has been established for more than two decades, subcloning large DNA fragments remains a rather challenging maneuver $(15,18)$. Our previous experience with the construction of the AdEasy ${ }^{\mathrm{TM}}$ (www.coloncancer.org/ adeasy.htm) and other large vectors suggested that the cloning efficiency of large DNA molecules might be affected by the copy number of a given vector. Higher cloning efficiency was seemingly associated with the use of a lower copy number vector (12). This phenomenon was particularly true when larger inserts (e.g., >3 kb) or larger destination constructs (e.g., >10 kb) were involved. In this report, we sought to test the above observations using a more definitive approach.

To ensure that a lower copy number vector was structurally comparable to a high copy number vector (i.e., pSL301; Invitrogen, Carlsbad, CA, USA), we engineered the pMOLUC vector that contains a pBR322-derived replicator. Specifically, a 507-bp fragment containing the MCS was PCR-amplified from a pSL301 vector using the M13 forward and M13 reverse primers, $5^{\prime}$-GTAAA ACGACGGCCAGT-3' and 5'-GGAA 


\section{Benchmarks}

ACAGCTATGACCATG-3'. The amplified fragment was blunt-ended and subcloned into the pBR322 vector at the blunted EcoRI and BspEI sites. The DNA sequence at the cloning junctions and the insert orientation were verified by DNA sequencing and restriction digestions. Figure 1A illustrates that the pMOLUC vector has a backbone similar to that of pSL301, except that the replicator of pMOLUC was derived from a pBR322 plasmid (2). The fulllength sequence of pMOLUC is available at http://mywebpage.netscape. com/ucmolab/home.html

To generate a pool of DNA fragments of various sizes, we used a recombinant adenoviral plasmid (approximately $34 \mathrm{~kb}$ ). When this plasmid was digested with $N c o I$, more than 20 fragments were produced with a broad range of size distribution: one fragment was less than $100 \mathrm{bp}$; five fragments were $100 \mathrm{bp}$ to $1 \mathrm{~kb}$; 10 fragments were $1-2 \mathrm{~kb}$; one fragment was $2-3 \mathrm{~kb}$; and three fragments were greater than $4 \mathrm{~kb}$. However, please note that potential partial digestions and/or possible con-

A

Potpisther Stous

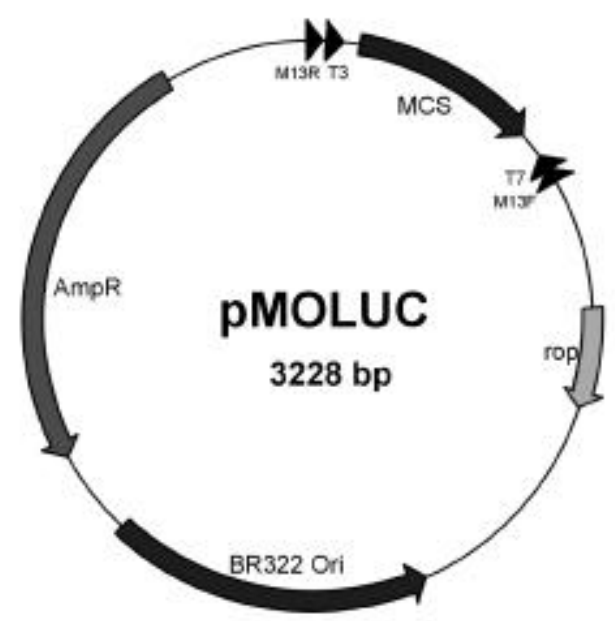

B

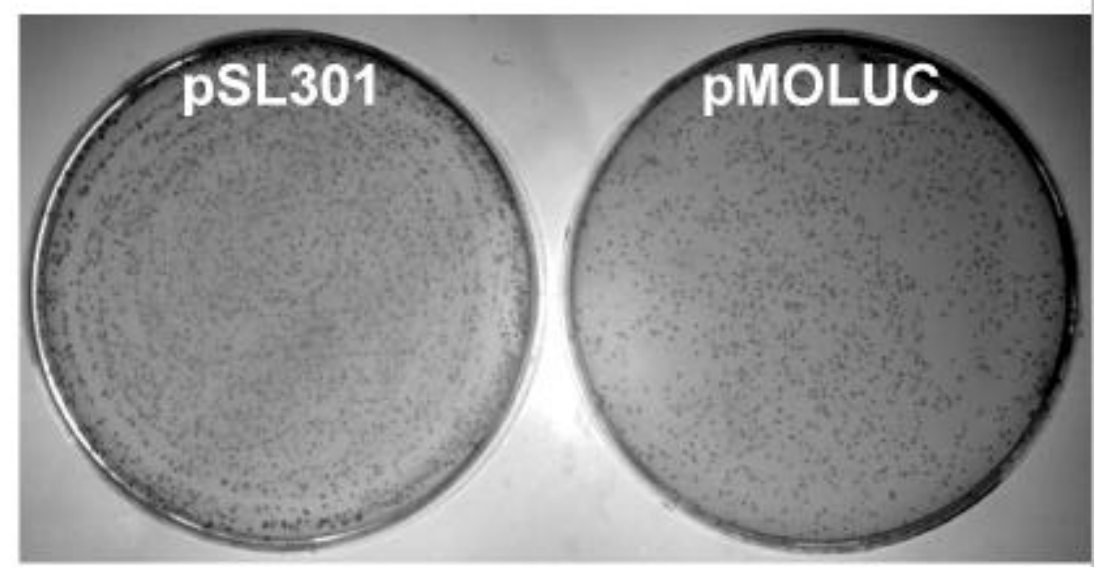

Figure 1. The pMOLUC vector map and the comparison of ligation efficiency between pMOLUC and pSL301. (A) Schematic representation of the pMOLUC vector. See text for construction detail. Fulllength sequence of this vector is listed at http://mywebpage.netscape.com/ucmolab/home.html. MCS, multiple cloning site; M13F, M13 forward primer sequence; M13R, M13 reverse primer sequence; and $\mathrm{T} 3$ and T7, T3 and T7 promoter/primer sequences, respectively. (B) Recombinant colonies resulted from subcloning in pSL301 and pMOLUC vectors. The ligation products were transformed into DH10B $E$. coli cells by electroporation. Approximately one-fifth of the transformation mixture was plated on LB/ampicillin plates, and recombinant DNA clones were selected and grown overnight. 


\section{Benchmarks}

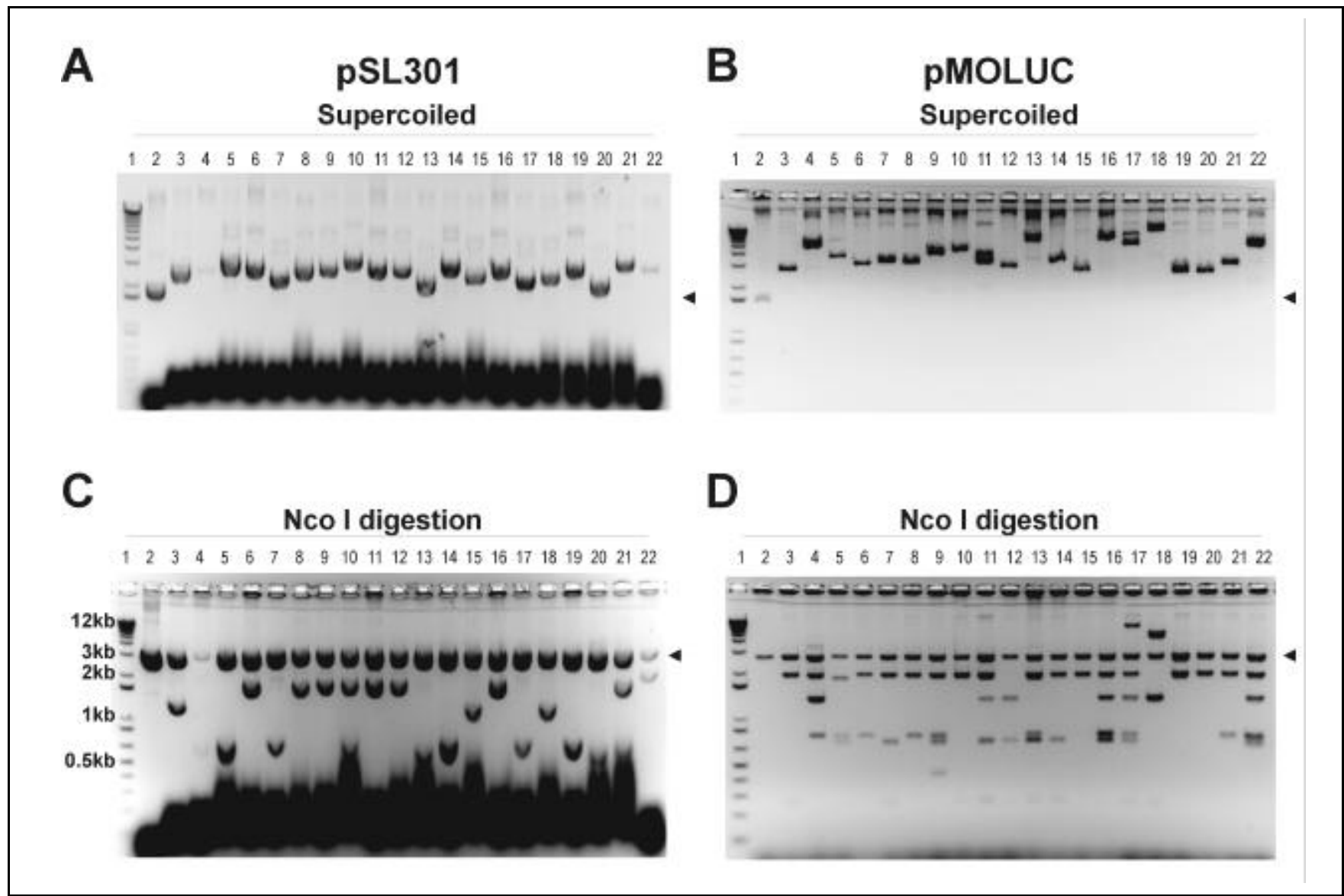

Figure 2. Restriction analysis of recombinant DNA clones derived from pSL301 and pMOLUC vectors. Twenty colonies for each ligation (Figure 1B) were randomly picked up and grown for plasmid DNA purification. Approximately one-tenth (i.e., $5 \mu \mathrm{L}$ ) of each miniprep DNA was either directly loaded onto and resolved on $0.8 \%$ agarose gels (A and B) or subjected to $N c o$ I digestions, followed by resolution on $1.0 \%$ agarose gels $(\mathrm{C}$ and $\mathrm{D})$. The $1 \mathrm{~Kb}$ Plus Ladder ${ }^{\mathrm{TM}}$ (Invitrogen) was used as a size marker (lane 1). Positions of the vector controls (lane 2) are indicated by arrows.

catamerization of digested fragments would likely shift the size distribution to larger fragments. The plasmid $(5 \mu \mathrm{g})$ was digested with $N c o$ I, followed by the subcloning of the digested DNA pool into the NcoI site of the pMOLUC and pSL301 vectors with T4 DNA ligase (Invitrogen) at $16^{\circ} \mathrm{C}$ for $4 \mathrm{~h}$. To reduce the ligation background, the NcoIdigested vectors were treated with calf intestinal alkaline phosphatase (New England Biolabs, Beverly, MA, USA). Ligation products were transformed into DH10B E. coli cells, and recombinants were selected on LB/ampicillin plates at $37^{\circ} \mathrm{C}$. When the same amounts of pMOLUC and pSL301 vectors were used for ligation and transformation, the pSL301-based ligation yielded more colonies, approximately two times those of pMOLUC (Figure 1B).

Recombinant colonies were random ly picked up and grown in $2 \mathrm{~mL}$ $\mathrm{LB} /$ ampicillin $(50 \mu \mathrm{g} / \mathrm{mL})$ in a $37^{\circ} \mathrm{C}$ environmental shaker overnight. The plasmids were purified using the alkaline lysis procedure. After being resolved on $0.8 \%$ agarose gels, the majority of clones derived from pMOLUC were significantly larger than those from pSL301 (Figure 2, compare A and B). These results were further confirmed by restriction digestion. When digested with $N c o$ I, most of the clones derived from pSL301 produced an insert smaller than $2 \mathrm{~kb}$ (Figure 2C). Conversely, most of the clones derived from pMOLUC yielded significantly larger inserts (Figure 2D). Specifically, all of the clones derived from pMOLUC contained an insert greater than $2 \mathrm{~kb}$, and $50 \%$ (10 of 20) of them contained an insert larger than $3 \mathrm{~kb}$ (Figure 2D, lanes 4, $5,9-11,13,16-18$, and 22). One clone even contained an insert that was greater than $7 \mathrm{~kb}$ (Figure 2D, lane 18). It should be pointed out that one of the clones (Figure 2, B and D, lane 17) might be a mixture of two separate clones, although it seemed that both clones contained large inserts. Thus, our results have demonstrated that pMOLUC indeed exhibits a higher cloning efficiency for larger DNA fragments than pSL301, which suggests that the cloning efficiency of large DNA molecules could be significantly improved by using a lower copy number vector. It should be pointed out that cloning large DNA fragments into a high copy number plasmid vector is still possible; however, it is more difficult (23).

In addition to containing the pBR322-derived replicator, pMOLUC represents a versatile cloning vector with a superlinker containing more 
than 56 unique cloning sites, which is flanked by M13 forward and M13 reverse primer sequences. This vector also contains the $\mathrm{T} 3$ and $\mathrm{T} 7$ promoters flanking the linker site, which are suitable for in vitro transcription from either strand. Several studies have reported the construction and utility of lower copy number vectors in molecular cloning $(7,24)$.

One possible drawback of using a lower copy number vector is that the DNA yield is lower. Because the replication of pMB1-derived plasmids does not require plasmid-coded factors and relies entirely on long-lived host enzymes, a practical means to increase plasmid yield is to add antibiotics such as chloramphenicol or spectinomycin at the early stage of amplification. These drugs can inhibit host protein synthesis and prevent replication of bacterial chromosome, while the plasmids continue to replicate until several thousand copies accumulate in the host cell (8). Nevertheless, the quantity of DNA obtained from a routine amplification should be sufficient for most molecular and cell biology experiments. Interestingly, several low copy number replicator-based vectors (i.e., <20 copies per cell) have been used for constructing YAC or BAC genomic DNA libraries (17). Although subcloning a large fragment (e.g., >100 kb) into these vectors is efficient, the extremely low DNA yield prevents their widespread use in molecular cloning experiments. Therefore, the pBR322-based vectors (e.g., pMOLUC) are probably the preferred choice for most conventional cloning experiments because they provide a high cloning efficiency for large DNA fragments (up to $30 \mathrm{~kb}$ ) yet produce a reasonable quantity of DNA.

\section{REFERENCES}

1.Actis, L.A., M.E. Tolmasky, and J.H. Crosa. 1999. Bacterial plasmids: replication of extrachromosomal genetic elements encoding resistance to antimicrobial compounds. Front. Biosci. 4:D43-62.

2.Balbas, P., X. Soberon, F. Bolivar, and R.L. Rodriguez. 1988. The plasmid, pBR322. Biotechnology 10:5-41.

3.Bolivar,F. 1978. Construction and characterization of new cloning vehicles, III. Derivatives of plasmid pBR322 carrying unique EcoRI sites for selection of $E c o$ RI generated recombinant DNA molecules. Gene 4:121-136.
4.Bolivar, F. 1979. Molecular cloning vectors derived from the CoLE1 type plasmid pMB1. Life Sci. 25:807-817.

5.Bolivar, F., R.L. Rodriguez, P.J. Greene, M.C. Betlach, H.L. Heyneker, and H.W. Boyer. 1977. Construction and characterization of new cloning vehicles, II. A multipurpose cloning system. Gene 2:95-113.

6.Botstein, D. 1999. Of genes and genomes. Ann. NY Acad. Sci. 882:32-65.

7.Churchward, G., D. Belin, and Y. Nagamine. 1984. A pSC101-derived plasmid which shows no sequence homology to other commonly used cloning vectors. Gene 31:165-171.

8.Clewell, D.B. 1972. Nature of Col E 1 plasmid replication in Escherichia coli in the presence of the chloramphenicol. J. Bacteriol. 110:667676.

9.Cohen, S.N. 1993. Bacterial plasmids: their extraordinary contribution to molecular genetics. Gene 135:67-76.

10.Cohen, S.N., A.C. Chang, H.W. Boyer, and R.B. Helling. 1973. Construction of biologically functional bacterial plasmids in vitro. Proc. Natl. Acad. Sci. USA 70:3240-3244.

11.del Solar, G. and M. Espinosa. 2000. Plasmid copy number control: an ever-growing story. Mol. Microbiol. 37:492-500.

12.He, T.-C., S. Zhou, L.T. da Costa, J. Yu, K.W. Kinzler, and B. Vogelstein. 1998. A simplified system for generating recombinant adenoviruses. Proc. Natl. Acad. Sci. USA 95:2509-2514.

13.Hershfield, V., H.W. Boyer, C. Yanofsky, M.A. Lovett, and D.R. Helinski. 1974. Plasmid ColEl as a molecular vehicle for cloning and amplification of DNA. Proc. Natl. Acad. Sci. USA 71:3455-3459.

14.Holtzman, N.A. and T. M. Marteau. 2000. Will genetics revolutionize medicine? $\mathrm{N}$. Engl. J. Med. 343:141-144.

15.Kaufman, R.J. 2000. Overview of vector design for mammalian gene expression. Mol. Biotechnol. 16:151-160.

16.Khan, S.A. 1997. Rolling-circle replication of bacterial plasmids. Microbiol. Mol. Biol. Rev. 61:442-455.

17.Monaco, A.P. and Z. Larin. 1994. YACs, BACs, PACs, and MACs: artificial chromosomes as research tools. Trends Biotechnol. 12:280-286.

18.Muyrers, J.P., Y. Zhang, and A.F. Stewart. 2001. Techniques: recombinogenic engineering - new options for cloning and manipulating DNA. Trends Biochem. Sci. 26:325-331.

19.Novick, R.P. 1998. Contrasting lifestyles of rolling-circle phages and plasmids. Trends Biochem. Sci. 23:434-438.

20.Rasooly, A. and R.S. Rasooly. 1997. How rolling circle plasmids control their copy num ber. Trends Microbiol 5:440-446.

21.Roses, A.D. 2000. Pharmacogenetics and the practice of medicine. Nature 405:857-65.

22.Sutcliffe, J.G. 1978. pBR322 restriction map derived from the DNA sequence: accurate DNA size markers up to 4361 nucleotide pairs long. Nucleic Acids Res. 5:2721-2728.

23.Tao, Q. and H.B. Zhang. 1998. Cloning and stable maintenance of DNA fragments over $300 \mathrm{~kb}$ in Escherichia coli with conventional plasmid-based vectors. Nucleic Acids Res. 26:4901-4909.
24.Wang, R.F. and S.R. Kushner. 1991. Construction of versatile low-copy-number vectors for cloning, sequencing and gene expression in Escherichia coli. Gene 100:195-199.

25. Watson, N. 1988. A new revision of the sequence of plasmid pBR322. Gene 70:399403.

26. Yanisch-Perron, C., J. Vieira, and J. Messing. 1985. Improved M13 phage cloning vectors and host strains: nucleotide sequences of the M13mp18 and pUC19 vectors. Gene 33:103-119.

This work was supported in part by research grants from the Concern Foundation, the Schweppe Foundation, and the Brinson Foundation (T.-C.H.). We wish to thank Bert Vogelstein of Johns Hopkins Oncology Center for the provision of pSL301 and for his encouragement on the reported work. We also thank Drs. Michael A. Simon and Terrance Peabody of The University of Chicago Medical Center for their support. The full-length sequence of pMOLUC and its vector map are listed at http://myweb page.netscape.com/ucmolab/ home.html. Researchers who wish to obtain the pMOLUC vector may send requests to tche@surgery.bsd.uchicago.edu. Address correspondence to Dr. Tong-Chuan He, Assistant Professor and Director, Molecular Oncology Laboratory, The University of Chicago Medical Center, 5841 S. Maryland Ave., MC 3079, Chicago, IL 60637, USA. email: tche@surgery.bsd.uchicago.edu

Received 7 December 2001; accepted 6 February 2002.

T. Feng ${ }^{1,2}$, Z. Li ${ }^{3}$, W. Jiang ${ }^{1}$, B. Breyer $^{1}$, L. Zhou', ${ }^{1,2}$ H. Cheng1, R.C. Haydon 1 , A. Ishikawa ${ }^{1,4}$, M.A. Joudeh ${ }^{1}$, and T. -C. He ${ }^{\mathbf{1}}$ ${ }^{1}$ The University of Chicago Medical Center

Chicago, IL, USA

${ }^{2}$ Chongqing University of

Medical Sciences

${ }^{3}$ Zhongshan Hospital

Chongqing, China

${ }^{4}$ Yamagata University

School of Medicine

Yamagata, Japan

For reprints of this or any other article, contact Reprints@BioTechniques.com 